\title{
Sulfonation of Divinylbenzene Adsorbents Packed in a Micro Sampler to Extract Airborne Organic Compounds
}

\author{
Po-Jung Huang ${ }^{1}$, Wen-Hsi Cheng ${ }^{2 *}$, Chia-Yu Chang ${ }^{2}$ \\ ${ }^{1}$ Institute of Environmental Engineering, National Sun Yat-Sen University, Kaohsiung 80424, \\ Taiwan \\ ${ }^{2}$ Department of Occupational Safety and Hygiene, Fooyin University, Kaohsiung 83102, Taiwan
}

\section{ABSTRACT}

In this work, sulfonated divinylbenzene (SDVB) adsorbents, with the 60-80 mesh diameter, were packed inside a 22-gauge stainless steel needle to fabricate a sulfonated needle trap sampler (SNTS), which is a micro sampler. An analysis of Fourier-transform infrared spectroscopy (FTIR) scanning data, thermal gravimetric analysis (TGA) data, and scanning electron microscopice (SEM) observations, confirmed the physiochemical characteristics of sulfonated DVB adsorbent resins. A gas mixture of approximately $20 \mathrm{ppm}$ of ethanol, methyl ethyl ketone (MEK), benzene, toluene, ethylbenzene and $o$-xylene (BTEX) was prepared to evaluate the sampling efficacies of the SNTS. The results reveal that, in 1-2 h, SNTS adsorbed increased $92-116 \%$ more methanol and $12-20 \%$ more MEK than NTS. The SNTS adsorbed 4-15\% less BTEX than the NTS. The tested SNTS exhibited remarkable adsorption capacities of methanol, which emitted in a metal frame manufacturing plant. The SNTS is recommended as an alternative passive sampler to the active adsorbent tubes.

Keywords: Sulfonation, Divinylbenzene, Adsorption, Micro sampler, Solid phase, Microextraction

\section{INTRODUCTION}

\section{OPEN ACCESS}

Received: June 30, 2021

Revised: August 25, 2021

Accepted: August 28, 2021

\section{${ }^{*}$ Corresponding Author:}

PL031@fy.edu.tw

\section{Publisher:}

Taiwan Association for Aerosol Research

ISSN: $1680-8584$ print ISSN: 2071-1409 online

\section{Copyright: The Author(s).} This is an open access article distributed under the terms of the Creative Commons Attribution License (CC BY 4.0), which permits unrestricted use, distribution, and reproduction in any medium, provided the original author and source are cited.

Solid phase microextraction (SPME) involves the adsorption of analytes by extracting phases, and relevant technology has been developed for over 30 years. SPME was developed as a solventfree technique for preparing samples using less than $1 \mu \mathrm{L}$ of an extracting phase. The extracting phase can be a solid sorbent, which is packed inside a stainless needle, and is typically of high porosity to provide a high surface area for adsorption (Pawliszyn, 1999).

To adsorb organic compounds in the liquid, gaseous or solid phases, various adsorbents must be used. Polar adsorbents are effective for extracting polar analytes and nonpolar adsorbents are effective for extracting nonpolar analytes from various matrices (Pawliszyn and Mani, 1999). Divinylbenzene (DVB) is a universal semipolar particle adsorbent with a high specific surface area of $750 \mathrm{~m}^{2} \mathrm{~g}^{-1}$ using to sample many gaseous organic compounds in the environment and working places (Cheng et al., 2017; Cheng and Wu, 2019; Cheng et al., 2020; Cheng and Yuan, 2021). DVB has higher adsorption capacities for $C_{6}-C_{15}$ compounds than for $C_{1}-C_{3}$ alcohols and ketones, including methanol, ethanol, propanol and methyl ethyl ketone (MEK) (Pawliszyn and Mani, 1999).

Adsorbents whose surface have been modified with specific functional groups have been proved to be the feasible for the adsorbing of mixed compounds. To increase the adsorption capacities of polychlorinated dibenzo- $p$-dioxins and -furans (PCDD/Fs) by activated carbon, Atkinson et al. (2015) developed carbon-based adsorbents by adding specific functional groups, including oxygen, sulfur, bromine and nitrogen. Tests revealed that modified carbons increased the removal efficiencies of PCDD/F to over $98 \%$. Organic compounds have been also used as functional groups to modify the surface characteristics of adsorbents. Janus et al. (2011) modified the mesoporous silica support, MCM-41, by introducing polyacrylonitrile (PAN) with an optimal PAN/MCM-41 mass ratios of 0.1 for 
eliminating gaseous MEK, achieving adsorption capacities of over $0.275 \mathrm{~g} \mathrm{MEK} \mathrm{g}^{-1}$ adsorbent. $\mathrm{Mu}$ et al. (2018) used organosilanes, including phenyltriethoxysilane (PTES), aminopropyltriethoxysilane (APTES), and trimethylchlorosilane (TMCS), to modify the adsorption capacities of diatomite (DE) for methane in the flue gas. Their experimental results revealed that PTES-DE and APTES-DE have excellent methane adsorption capacities at room temperature and low operation pressures of 37.5 bar. Polyethyleneimine has been used for increasing the adsorption capacities of formaldehyde by carbon nanotubes (Song et al., 2018). Ethylene-diamine has been used for modify diatomaceous earth to adsorb formaldehyde (Bernabe et al., 2015).

Lou et al. (2018) coated polystyrene-divinylbenzene (PSDVB) with graphene to modify it to increase its organic adsorption capacities. They separated ten allergenic disperse dyes from industrial wastewater using SPME samplers with detection limits of 1.1-15.6 ng mL $\mathrm{L}^{-1}$. Sulfonated porous PSDVB has been used in the hydrophilic and chiral separation of oxalic acid, formic acid, acetic acid, acrylic acid (Cong et al., 2020), and separation of aromatic matrices, including 1,4hydroquinone, benzoic acid, phenol, benzaldehyde and toluene (Huang et al., 2018). PSDVB magnetic porous microspheres have been prepared by sulfonation to adsorb 2,4-dichlorophenol and 2,4,6-trichlorophenol from aqueous solution (Yu et al., 2015).

The SPME micro sampler, which is a needle trap sampler (NTS), was developed over a decade by Cheng et al. $(2017,2019,2020,2021)$ to collect airborne organic compounds. Notably, PDVB particles with diameters of 60-80 meshes were used as the packed adsorbent as its most proper operation among different sizes of particles for packing inside a needle. The traditional DVB-NTS exhibits excellent efficiencies of adsorption of aromatic compounds; however, $\mathrm{C}_{1}-\mathrm{C}_{3}$ alcohols and ketones, which are extensively used in industry as solvents, cannot be extracted effectively by a DVB-NTS. Sulfonation has been successfully used to modify adsorption characteristics of various adsorbents (Liu et al., 2010; Azhagapillai et al., 2020; Khomein et al., 2021). In this work, sulfonated PDVB particles with diameters of 60-80 meshes were packed inside 22-gauge stainless steel needles to extract mixed organic compounds.

\section{METHODOLOGY}

\subsection{Extraction of Gaseous Compounds Using Needle Trap Samplers}

An NTS extracts gaseous chemical compounds through the needle by air diffusion. $A$ linear gaseous concentration profile $(C(Z)$ in Fig. 1$)$ is obtained along the diffusion path $(Z)$, and the extraction of the analyte is characterized by the area $(A)$ of opening and the length of the diffusion path in the needle. The total extracted mass $(n)$ of analyte in a time interval $(t)$ is estimated using Eq. (1) (Lord, et al., 2010).

$n=D_{m} \frac{A}{Z} \int C(t) d t$

where $D_{\mathrm{m}}$ is the diffusion coefficient of the extracted analyte. Accordingly, the quality $(n)$ of the extracted analyte is assumed to be proportional to the weighted average (TWA) concentration $(C(t))$, given a constant $D_{\mathrm{m}}$, a uniform needle opening $(A)$, and a fixed diffusion path length $(Z)$.

\subsection{Preparation of Needle Trap Samplers}

The NTS consists of a 22-gauge stainless steel needle that is packed with DVB adsorbent of a size consistent with 60-80 mesh. The diameter of a 22-gauge needle corresponded to the size of injection port of gas chromatograph (GC). DVB particles were packed by aspiration to the desired length of $7 \mathrm{~mm}$ and a diffusion path length of $3 \mathrm{~mm}$ (Fig. 1). A very small amount of epoxy glue was applied to the exposed portion of the adsorbent layer to immobilize the DVB particles. To prevent blockage by an NTS epoxy-resin plug, air was drawn continuously through the NTS packing phase as the epoxy cured. Finally, the DVB in the NTS was conditioned by heating at the injection port of the $\mathrm{GC}$ to $280^{\circ} \mathrm{C}$ for $30 \mathrm{~min}$.

The uniformity of the packing phase in an NTS was studied by a procedure that has described in earlier works (Cheng et al., 2017; Cheng and Wu, 2019; Cheng et al., 2020; Cheng and Yuan, 2021). The desired air exhaustion rate through the NTS was obtained by drawing air through the 


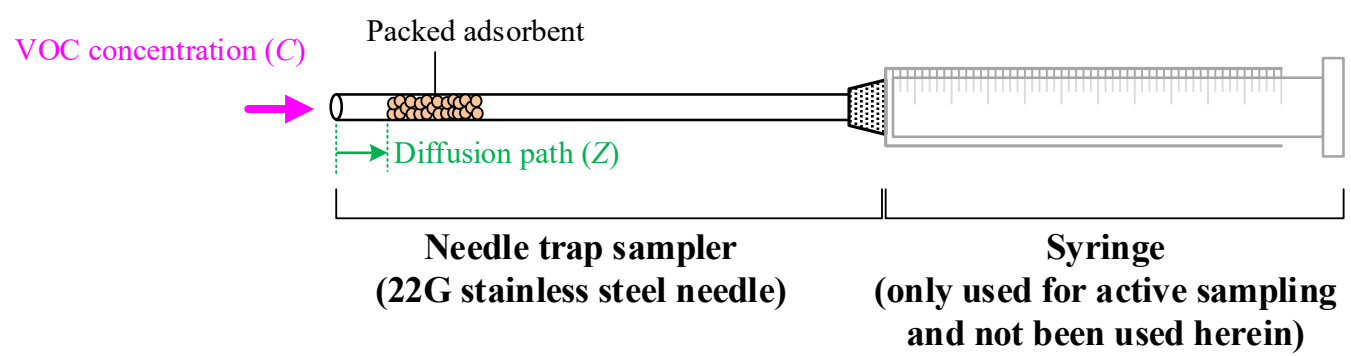

Fig. 1. Schematic needle trap sampler (NTS).

packing phase using an aspirating pump. When the relative standard deviation (RSD) of the air flow rates in triplicate tests did not exceed $5 \%$, the packed materials inside the NTS were assumed to be uniformly immobilized. Gaseous standard samples of a mixture of benzene, toluene, ethylbenzene (EB) and o-xylene (BTEX) (around $20 \mathrm{ppm}$ ) were prepared in a $500 \mathrm{~mL}$ Pyrex glass bulb, in which the NTS was inserted for $1 \mathrm{~h}$ or $2 \mathrm{~h}$ to adsorb BTEX. When the RSD of the sampled mass in triplicate tests was less than $10 \%$, the tested NTS was ready for use. An SNTS, which was packed with SDVB, was also prepared by the procedures that was used to prepare the NTS. Ethanol and MEK were also mixed with BTEX to assess the effectiveness of the SDVB adsorbent for extracting mixed VOCs.

\subsection{Sulfonation Synthesis of Adsorbent Divinylbenzene Resins}

Sulfonated DVB (SDVB) was synthesized by sulfonation using a modified version of the method that was used by Liu et al. (2010) and Khomein et al. (2021). $3 \mathrm{~g}$ mass of DVB resin was swollen in dichloromethane (DCM) for $24 \mathrm{~h}$. The swollen DVB resin was transferred into a three-neck round bottle. A $45 \mathrm{~mL}$ volume of concentrated sulfonic acid was added dropwise to the bottle and reacted with the swollen DVB at $90^{\circ} \mathrm{C}$ for $1 \mathrm{~h}$. Thereafter, $100 \mathrm{~mL}$ of deionized water was slowly added to dilute the concentrated sulfonic acid solution. The final product, SDVB adsorbent was dried in an oven at $50^{\circ} \mathrm{C}$.

Fourier-transform infrared spectroscopy (FTIR, Thermo Nicolet iS5, USA) was used to identify the chemical structure of SDVB, and especially to verify that the sulfonation was complete. A scanning electron microscope (SEM, FEI Quanta-200, Hillsboro, OR) with a scanning range from 400 to $4,000 \mathrm{~cm}^{-1}$ was used to observe the morphology of the DVB resin following sulfonation. Thermal gravimetric analysis (TGA, TA Q50, New Castle, DE) was performed to determine the thermal properties of the SDVB adsorbent and to optimize the operating conditions for regeneration. TGA was conducted in the range from 40 to $800^{\circ} \mathrm{C}$ at a scanning rate of $20^{\circ} \mathrm{C} \mathrm{min}^{-1}$.

\subsection{Chemicals, Materials and Instrumentation}

Stainless steel needles ( $22 \mathrm{G}$, length $7 \mathrm{~cm}$ and ID $0.41 \mathrm{~mm}$ ) were purchased from a local company (Herling Co. Ltd., Pingtung, Taiwan) for use in preparing the NTS. DVB resin was purchased from Supelco (Bellefonte, PA, USA). Aspirating pumps, which were used to determine the NTS sampling flow rates, were purchased from Kitagawa (AP-20, Kawasaki, Japan), and epoxy glue was purchased from Nao-Pao Applied Material Co. Ltd. (Taoyuan, Taiwan). All gases that were used in chromatographic analysis (Jing-De Gas Co., Ltd., Kaohsiung, Taiwan) were of ultra-high purity. All chemicals that were used in analysis and sulfonation synthesis were obtained from Sigma-Aldrich (Munich, Germany).

Gaseous samples were analyzed using a GC (6890N, Agilent, Wilmington, DE, USA) that was equipped with a flame ionization detector (FID). The capillary column was HP19091Z-413 HP-1 PDMS $(30 \mathrm{~m} \times 320 \mu \mathrm{m} \times 0.25 \mu \mathrm{m}$ ) (Agilent). The unknown chemical compounds were analyzed to determine the constituents using another gas chromatography-mass spectroscopy system (MS 5973, Agilent).

\subsection{Sampling and Analysis}

A target industrial site of Plant A, which is located in the Nanzih Export Processing Zone, Kaohsiung City, southern Taiwan, was monitored to determine workers' exposure to organic solvents. The 


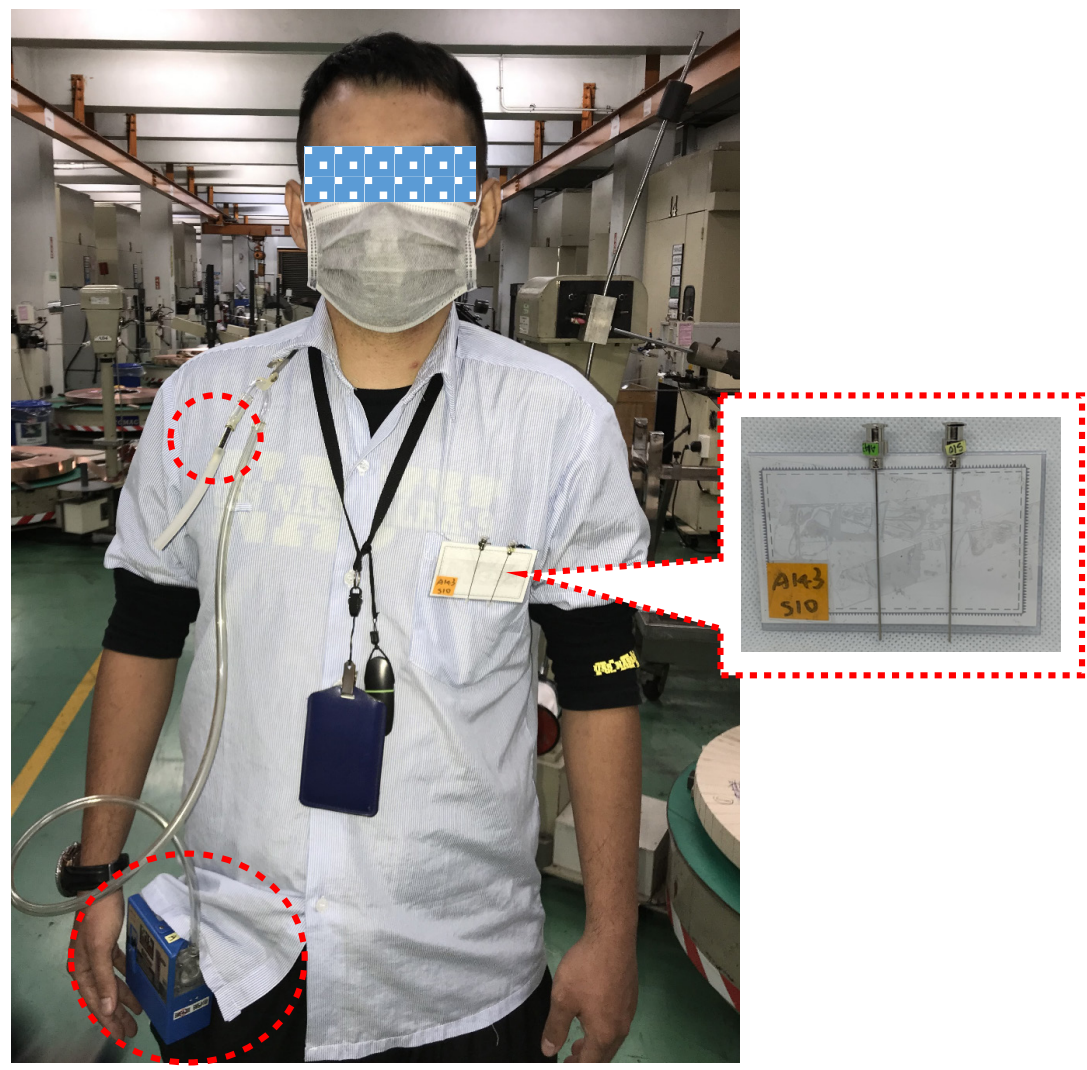

Fig. 2. The worker was wearing gas samplers. Left dotted circles: a charcoal tube and a sampling pump (the NIOSH sampling method); Right dotted box: Two types of NTS fixed on a plastic plate.

target plant mostly manufactures metal frames used in the semiconductor processing. Workers always used different tools for preparing machines and metal molds, therefore alcohols were used for wiping and grinding oils for repairing tools. Two types of micro samplers, an NTS and an SNTS fixed on a plastic sheet, were worn on workers' breathing zone (Fig. 2). Each worker also wore an other personal sampling device, comprising an adsorbent tube (Method 2000 for methanol and Method 1500 for alkanes (NIOSH, 2003)), which was connected to a personal air pumps for active sampling (Fig. 2). The solvent vapors in the adsorbent tubes after sampling were analyzed by a corporation that was contracted by the owners of Plant A to identify the compounds and their concentrations.

After sampling, each NTS and SNTS was taken to the laboratory and inserted into the injection ports of a GC-FID to desorb analytes for analysis. The desorption time and temperature at the injection port were $30 \mathrm{~s}$ and $250^{\circ} \mathrm{C}$, respectively. The temperature of the $\mathrm{GC}$ was increased from $50^{\circ} \mathrm{C}$ in increments of $15^{\circ} \mathrm{C} \mathrm{min}^{-1}$ to $180^{\circ} \mathrm{C}$, which was held for $2 \mathrm{~min}$. The FID detector was heated to $300^{\circ} \mathrm{C}$. The flow rate of the carrier gas, nitrogen, was $1.2 \mathrm{~mL} \mathrm{~min}^{-1}$, and the split-off operating mode was used. The calibration analysis for analytes were implemented following the same operating procedures.

\section{RESULTS AND DISCUSSIONS}

\subsection{Characteristics of Sulfonated Divinylbenzene Adsorbent}

Fig. 3 presents the FTIR spectrum of DVB and SDVB. The OH stretching and scissoring vibration for $\mathrm{H}_{2} \mathrm{O}$ were observed at 3,449 and $1,632 \mathrm{~cm}^{-1}$, respectively. Compared with DVB, these peaks in SDVB exhibited higher intensity than in DVB indicating sulfonation of DVB would effectively improve the hydrophilicity. Vrancken et al. (2017) also reported that the hydrophilicity would performed higher peak intensity of water compared with hydrophobic surface. The characteristic peaks of SDVB were observed at approximately 1,323,1,176,1,069,1,007 and $6121 \mathrm{~cm}^{-1}$. The 


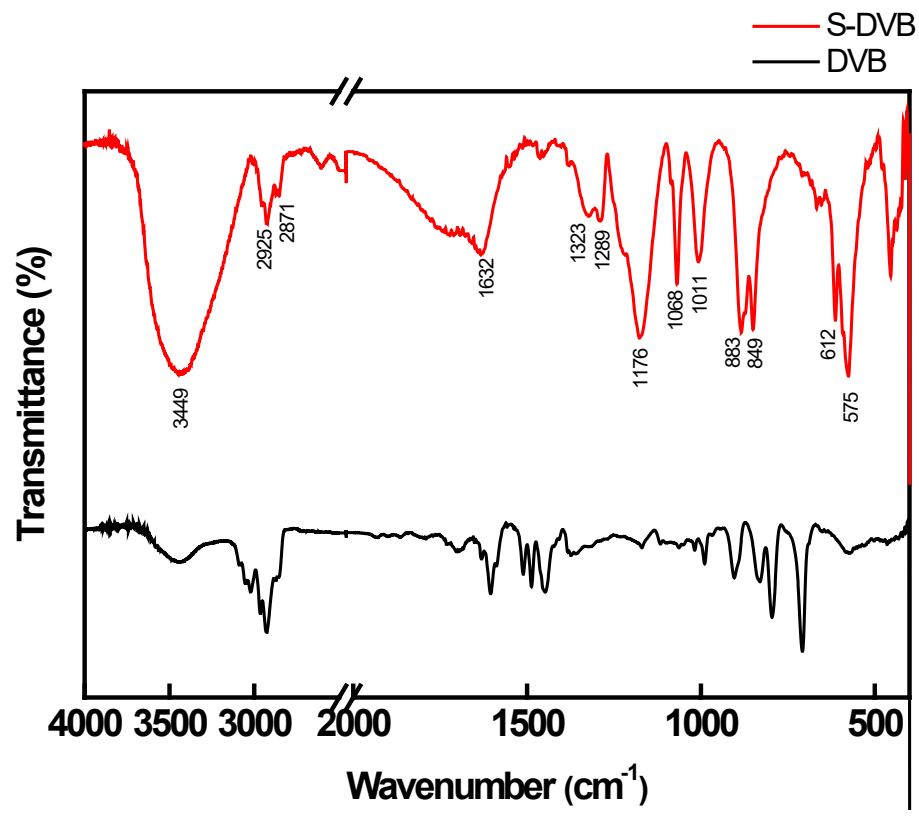

Fig. 3. FTIR spectra of divinylbenzener resin (DVB) and sulfonated DVB (SDVB).
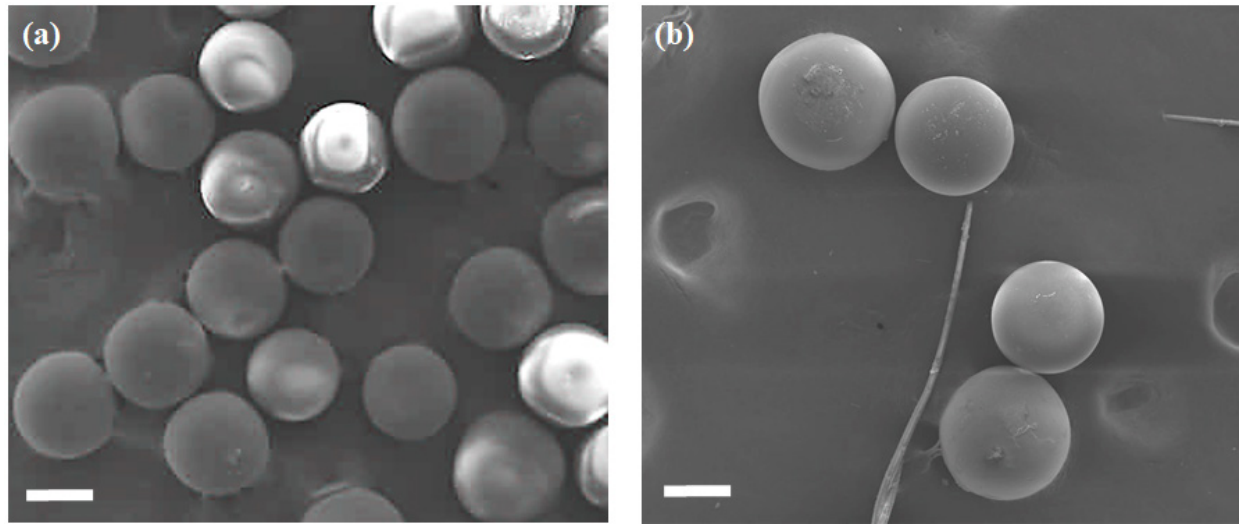

Fig. 4. SEM image of resin: (a) DVB; (b) SDVB (scale bar: $100 \mu \mathrm{m}$ ).

peaks at 1,323 $1 \mathrm{~cm}^{-1}$ to the asymmetric stretching vibration of $\mathrm{S}=0$ and the peak at 1,069 and $1,0071 \mathrm{~cm}^{-1}$ corresponded to the symmetric stretching vibration of $S=O$. The peak at $6121 \mathrm{~cm}^{-1}$ corresponded to the $\mathrm{C}-\mathrm{S}$ bending vibration.

Fig. 4 displays SEM images of DVB and SDVB. The resin comprised microspheres with diameters of 100-150 $\mu \mathrm{m}$. A comparison of DVB with SDVB revealed that treatment with sulfonic acid did not change the size or shape of the particles. The filling resin was regenerated at $280^{\circ} \mathrm{C}$. Therefore, the thermal properties of DVB and SDVB were determined by TGA and shown in Fig. 5. DVB began decomposing at $392.82^{\circ} \mathrm{C}$, and dramatically decreased at $405.4^{\circ} \mathrm{C}$. The decomposition temperature was $463^{\circ} \mathrm{C}$. Owing to the hydrophilicity of SDVB, moisture caused initial weight loss of SDVB at $187.01^{\circ} \mathrm{C}$. The decomposition of SDVB also occurred around $468^{\circ} \mathrm{C}$. TGA results also revealed that sulfonated DVB resins not only maintain their thermal properties but also exhibited hydrophilicity in the adsorption of polar hydrocarbons.

\subsection{Adsorption Tests of Sulfonated Divinylbenzene Adsorbent}

Fig. 6 shows the total mass (ng) of a 20-ppm mixture of gaseous BTEX, ethanol and MEK in a bulb that were adsorbed by the NTS and SNTS. Notably, the 2-h adsorption mass of organic compounds was approximately double the 1-h adsorption mass for all compounds indicating that the adsorption had not saturated at $1-2 \mathrm{~h}$, and the adsorption mass was proportional to the 


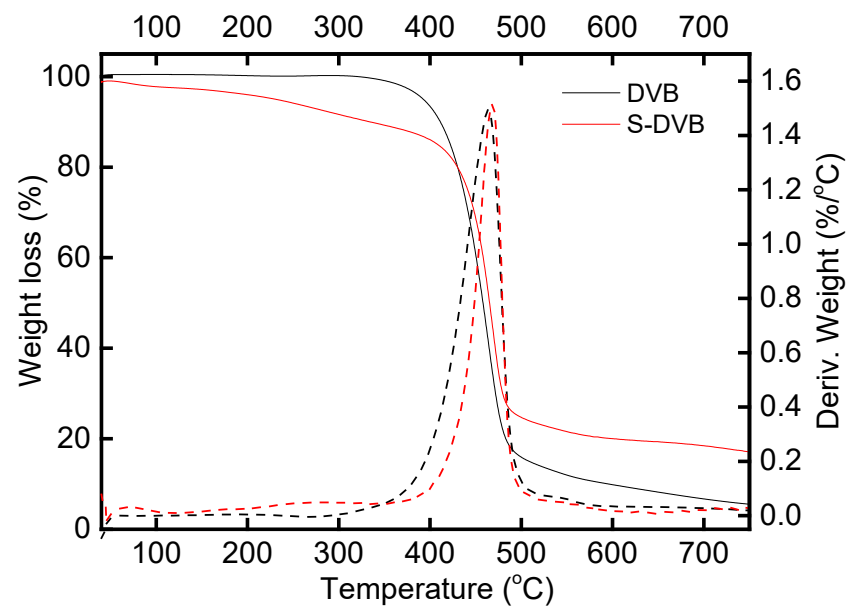

Fig. 5. Thermal gravimetric analysis of DVB and SDVB.

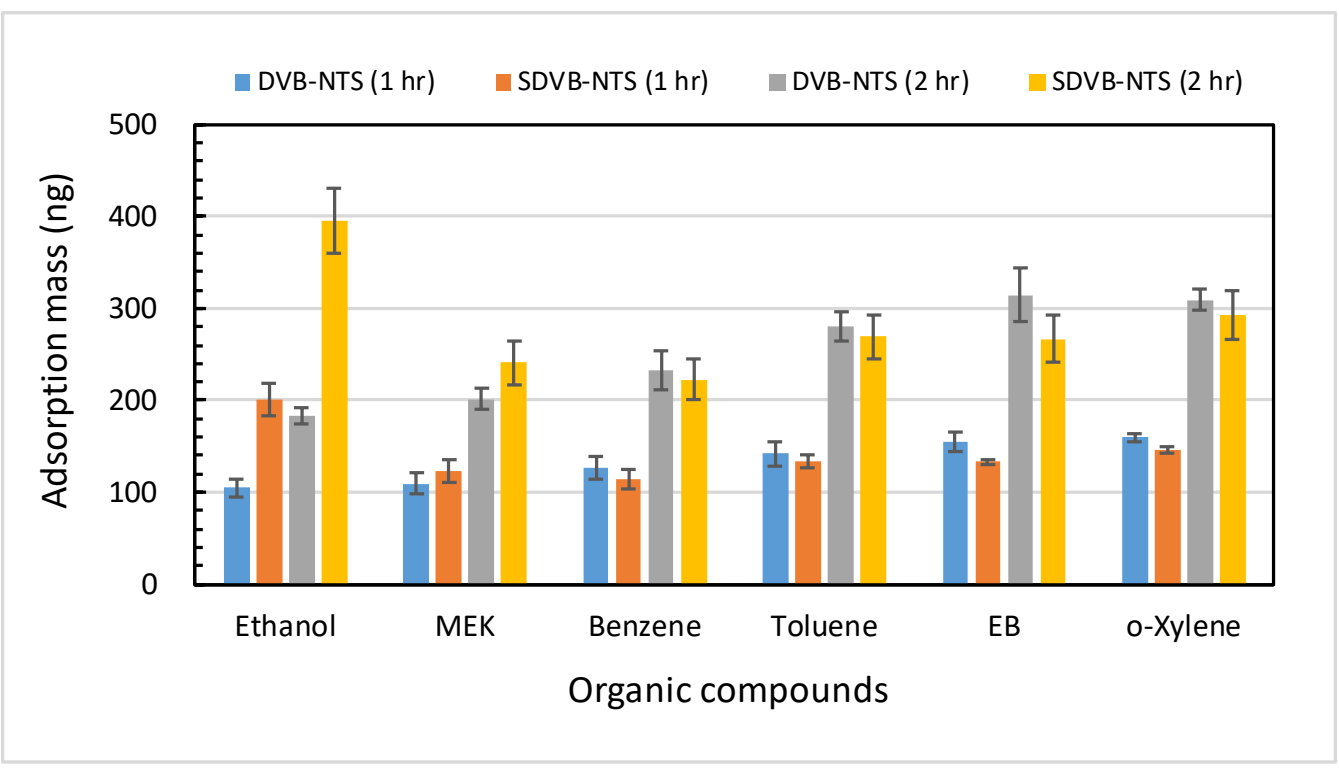

Fig. 6. Adsorption mass of organic compounds by NTS and SNTS.

sampling times. Table 1 presents the RSD values for NTS and SNTS in the extraction of BTEX, ethanol and MEK. A sampling times of either $1 \mathrm{~h}$ or $2 \mathrm{~h}$, all RSDs of the adsorption masses in duplicate tests of the NTS and SNTS were under $10 \%$. Accordingly, the procedures of preparing the NTS and the SNTS effectively ensured their extraction of gaseous BTEX, ethanol and MEK.

The SNTS adsorbed twice as much ethanol as did the NTS for adsorption periods of $1 \mathrm{~h}$ and $2 \mathrm{~h}$ (Fig. 6). The sulfonation of DVB improved the hydrophility of the adsorbent, so SDVB had a greater affinity than DVB for ethanol. However, the SNTS adsorbed $12 \%$ more MEK than did the NTS at $1 \mathrm{~h}$, and $20 \%$ more at $2 \mathrm{~h}$. According to the data in Fig. 6 , the mass of BTEX that was adsorbed by SNTS was a little lower than adsorbed by the NTS. The SNTS adsorbed $6-14 \%$ less than the NTS at $1 \mathrm{~h}$, and $4-15 \%$ less at $2 \mathrm{~h}$.

\subsection{Monitoring of Organic Vapor Emissions at a Working Place Using Micro Samplers}

Personal sampling devices, including passive NTS and active charcoal tubes, were simultaneously worn in the breathing zones by four selected operators at the target site (Fig. 2). Table 2 shows that the concentrations of low-polarity compounds ( $n$-hexane and iso-dodecane), that were measured using NTS, SNTS and adsorbent tubes, did not vary significantly from each other. The 
Table 1. Deviation distribution of three duplicate tests for needle trap samplers.

\begin{tabular}{lllll}
\hline \multirow{2}{*}{ Compounds } & \multicolumn{3}{c}{ Relative standard deviation (\%) } \\
\cline { 2 - 5 } & DVB-NTS $^{\mathrm{a}}(1 \mathrm{~h})$ & SDVB-NTS $^{\mathrm{a}}(\mathrm{h})$ & DVB-NTS $^{\mathrm{a}}(2 \mathrm{~h})$ & SDVB-NTS $^{\mathrm{a}}(2 \mathrm{~h})$ \\
\hline Ethanol & 9.6 & 9.2 & 4.7 & 8.9 \\
MEK & 9.7 & 9.8 & 6.0 & 10.0 \\
Benzene & 9.2 & 8.4 & 9.1 & 10.0 \\
Toluene & 10.0 & 5.6 & 5.6 & 8.8 \\
EB & 6.6 & 2.6 & 9.2 & 9.6 \\
o-Xylene & 2.9 & 2.6 & 3.9 & 9.1 \\
\hline
\end{tabular}

a Four DVB-NTS and four SDVB-NTS were prepared and tested.

Table 2. Workers' organic vapor exposures in the wiring frame processing plant.

\begin{tabular}{|c|c|c|c|c|c|c|}
\hline \multirow[t]{2}{*}{ Organic compounds } & \multicolumn{3}{|c|}{$\begin{array}{l}\text { Exposure concentrations from standing } \\
\text { processing (ppm) }\end{array}$} & \multicolumn{3}{|c|}{$\begin{array}{l}\text { Exposure concentrations from tooling } \\
\text { repair }(\mathrm{ppm})^{\mathrm{a}}\end{array}$} \\
\hline & NTS & SNTS & Adsorbent tube & NTS & SNTS & Adsorbent tube \\
\hline Methanol $^{\mathrm{b}}$ & $6.2 \pm 0.6$ & $15.2 \pm 0.3$ & 15.3 & $<0.26$ & $<0.26$ & $<0.32$ \\
\hline$n$-Hexane ${ }^{b}$ & $16.4 \pm 0.7$ & $17.7 \pm 1.5$ & 17.9 & $12.3 \pm 0.2$ & $12.4 \pm 1.8$ & 12.8 \\
\hline iso-Dodecane & $14.9 \pm 3.7$ & $14.5 \pm 3.5$ & N.A. ${ }^{c}$ & $6.6 \pm 1.6$ & $6.8 \pm 1.3$ & N.A. ${ }^{c}$ \\
\hline Toluene & $<0.15$ & $<0.15-0.44$ & N.A. ${ }^{c}$ & $<0.15$ & $<0.15$ & N.A. ${ }^{c}$ \\
\hline o-Xylene & $<0.14$ & $<0.14-0.59$ & N.A. ${ }^{c}$ & $<0.14$ & $<0.14$ & N.A. ${ }^{c}$ \\
\hline
\end{tabular}

${ }^{a}$ Concentrations are displayed as the actually detected ranges.

${ }^{b}$ Methanol was sampled and analyzed using Method 2000 and $n$-hexane using Method 1500 (NIOSH, 2003) by the contracted corporation.

${ }^{\mathrm{C}}$ N.A. (not available) indicates iso-dodecane, toluene and $o$-xylene were not analyzed by the contracted corporation.

NTS and the SNTS are alternatives to the standard method (Method 1500) for sampling lowpolarity hydrocarbons. The SNTS had better adsorption capacities than the NTS for methanol which has a high polarity, owing to the effect of sulfonation of the SDVB adsorbent. Notably, the concentrations of methanol, that were obtained by sampling by the SNTS and the Method 2000, were close to each other (15.2 $\pm 0.3 \mathrm{ppm}$ vs. $15.3 \mathrm{ppm})$. Therefore, the SNTS, which is packed with SDVB adsorbent, is a suitable sampler of hydrophilic and hydrophobic hydrocarbons for occupational health-related purposes.

The permissible exposure limits (PEL) for methanol is $200 \mathrm{ppm}$, and that for $n$-hexane is $50 \mathrm{ppm}$ (NIOSH, 2007). In Plant A, the exposure concentrations of methanol and $n$-hexane were lower the respective PELs for organic solvent operators. iso-Dodecane is a low-hazard petroleum hydrocarbon, which is often used as a thinner. The exposure concentrations of toluene and $o$-xylene were much lower than the PELs of 100 ppm (NIOSH, 2007). Based on the exposure concentrations in Table 2, the health risks of those organic solvents to workers are low and operational management of organic solvents in Plant $A$ is satisfactory.

\section{CONCLUSIONS}

In Taiwan, solvent vapors in a working environment must be monitored at least once every six months (Ministry of Labor, Taiwan, 2016). Accordingly, workers in Plant A, who used solvents that contain methanol and $n$-hexane, must wear an adsorbent tube and a sampling pump to sample organic vapors. The effectiveness of SNTS as an alternative sampler was evaluated in this work. The SNTS can be reused when the adsorbed analytes are thermally desorbed the insert port of a chromatograph, and SNTS analysis does not require solvents for extraction during the injection sample preparations. Additionally, an SNTS is small and very light, so a worker can wear it more easily than an NIOSH sampling device.

In this work, sulfonated DVB adsorbents, which were packed into SNTS to extract airborne organic compounds, were verified to be effective for adsorbing high-polarity hydrocarbons. For testing purposes, more organic compounds should be adsorbed by SDVB in the future, with a focus on 
those hazardous compounds, and those commonly used in industry, such as dimethylformamide (DMF), aniline, acetonitrile and pyridine.

\section{ACKNOWLEDGMENTS}

The authors would like to thank Mr. Chi-Sheng Pan for his assistance in sampling, and would like to thank the Ministry of Science and Technology of Taiwan, Republic of China, for financially supporting this research under contract MOST 108-2221-E-242-001.

\section{DISCLAIMER}

The authors declare no conflict of interest.

\section{SUPPLEMENTARY MATERIAL}

Supplementary material for this article can be found in the online version at https://doi. org/10.4209/aaqr.210157

\section{REFERENCES}

Atkinson, J.D., Hung, P.C., Zhang, Z., Chang, M.B., Yan, Z., Rood, M.J. (2015). Adsorption and destruction of PCDD/Fs using surface-functionalized activated carbons. Chemosphere 118, 136-142. https://doi.org/10.1016/j.chemosphere.2014.07.055

Azhagapillai, P., Pillai, V.V., Shoaibi, A.A., Chandrasekar, S. (2020). Selective adsorption of benzene, toluene, and m-xylene on sulfonated carbons. Fuel 280, 118667. https://doi.org/10.1016/j.fu el.2020.118667

Bernabe, D.P., Herrera, R.A.S., Doma Jr., B.T., Fu, M.L., Dong, Y., Wang, Y.F. (2015). Adsorption of low concentration formaldehyde in air using ethylene-diamine-modified diatomaceous earth. Aerosol Air Qual. Res. 15, 1652-1661. https://doi.org/10.4209/aaqr.2015.05.0292

Cheng, W.H., Huang, H.L., Chen, K.S., Chang, Y.J. (2017). Quantification of VOC emissions from paint spraying on a construction site using solid phase microextraction devices. J. Environ. Sci. Health A 52, 115-1163. https://doi.org/10.1080/10934529.2017.1356208

Cheng, W.H., Wu, H.M. (2019). Assessing organic chemical emissions and workers' risk of exposure in a medical examination center using solid phase microextraction devices. Aerosol Air Qual. Res. 19, 865-870. https://doi.org/10.4209/aaqr.2018.08.0288

Cheng, W.H., Huang, H.L., Chuang, M.H. (2020). Use of passive SPME sampling devices to determine exposure of oil painters to organic compounds. J. Air Waste Manage. Assoc. 70, 253259. https://doi.org/10.1080/10962247.2019.1694090

Cheng, W.H., Yuan, C.S. (2021). Using a micro sampler on a drone to extract organic vapors-A case study of monitoring industrial pollution. Aerosol Air Qual. Res. 21, 200359. https://doi.org/10.4209/aaqr.2020.06.0359

Cong, H., Xing, J., Ding, X., Zhang, S., Shen, Y., Yu, B. (2020). Preparation of porous sulfonated poly(styrene-divinylbenzene) microspheres and its application in hydrophilic and chiral separation. Talanta 210, 120586. https://doi.org/10.1016/j.talanta.2019.120586

Huang, Z., Yao, P., Zhu, Q., Wang, L., Zhu, Y. (2018). The polystyrene-divinylbenzene stationary phase hybridized with oxidized T nanodiamonds for liquid chromatograph. Talanta 185, 221228. https://doi.org/10.1016/j.talanta.2018.03.076

Janus, R., Kus, P., Dudek, B., Piwowarska, Z., Kochanowski, A., Michalik, M., Cool, P. (2011). Removal of methyl-ethyl ketone vapour on polyacrylonitrile-derived carbon/mesoporous silica nanocomposite adsorbents. Micropor. Mesopor. Mat. 145, 65-73. https://doi.org/10.1016/j.m icromeso.2011.04.029

Khomein, P., Ketelaars, W., Lap, T., Liu, G. (2021). Sulfonated aromatic polymer as a future proton exchange membrane: A review of sulfonation and crosslinking methods. Renewable Sustainable Energy Rev. 137, 110471. https://doi.org/10.1016/j.rser.2020.110471 
Liu, F., Meng, X., Zhang, Y., Ren, L., Nawaz, F., Xiao, F.S. (2010). Efficient and stable solid acid catalysts synthesized from sulfonation of swelling mesoporous polydivinylbenzenes. J. Catal. 271, 52-58. https://doi.org/10.1016/j.jcat.2010.02.003

Lord, H., Zhan, W., Pawliszyn, J. (2010). Fundamentals and applications of needle trap devices. Anal. Chim. Acta 677, 3-18. https://doi.org/10.1016/j.aca.2010.06.020

Lou, C., Wu, C., Zhang, K., Guo, D., Jiang, L., Lu, Y., Zhu, Y. (2018). Graphene-coated polystyrenedivinylbenzene dispersive solid-phase extraction coupled with supercritical fluid chromatography for the rapid determination of 10 allergenic disperse dyes in industrial wastewater samples. J. Chromatogr. A 1550, 45-56. https://doi.org/10.1016/j.chroma.2018.03.040

Ministry of Labor, Taiwan (2016). Regulations governing the monitoring of working environment. Taipei, Taiwan.

Mu, Y., Cui, M., Zhang, S., Zhao, J., Meng, C., Sun, Q. (2018). Comparison study between a series of new type functional diatomite on methane adsorption performance. Micropor. Mesopor. Mat. 267, 203-211. https://doi.org/10.1016/j.micromeso.2018.03.037

National Institute for Occupational Safety and Health (NIOSH) (2003). Manual of analytical methods, 4th Edition. Atlanta, GA, USA.

National Institute for Occupational Safety and Health (NIOSH) (2007). NIOSH pocket guide to chemical hazards, 3rd Printing. Atlanta, GA, USA.

Pawliszyn, J. (1999). Quantitative aspect of SPME, in: Pawliszyn, J. (Ed.), Application of solid phase microextraction. The Royal Society of Chemistry, UK, pp. 3-21.

Pawliszyn, J., Mani, V. (1999). Properties of commercial SPME coatings, in: Pawliszyn, J. (Ed.), Application of solid phase microextraction. The Royal Society of Chemistry, UK, pp. 57-72.

Song, S., Chen, D., Wang, H., Guo, Q., Wang, W., Wu, M., Yu, W. (2018). Film bulk acoustic formaldehyde sensor with polyethyleneimine-modified single-wall carbon nanotubes as sensitive layer. Sens. Actuators, B 266, 204-212. https://doi.org/10.1016/j.snb.2018.03.129

Vrancken, N., Sergeant, S., Vereecke, G., Doumen, G., Holsteyns, F., Terryn, H., De Gendt, S., Xu, X. (2017). Superhydrophobic breakdown of nanostructured surfaces characterized in situ using ATR-FTIR. Langmuir 33, 3601-3609. https://doi.org/10.1021/acs.langmuir.6b04471

Yu, P., Sun, Q., Li, J., Pan, J., Tan, Z., Yan, Y. (2015). Synthesis of poly (styrene-divinyl benzene) magnetic porous adsorbents prepared by sulfonation for the adsorption of 2,4-dichlorophenol and 2,4,6-trichlorophenol from aqueous solutions. Desalin. Water Treat. 56, 1610-1621. https://doi.org/10.1080/19443994.2014.950988 